\title{
Article \\ Carbide Precipitation in a Low Alloyed Steel during Aging Studied by Atom Probe Tomography and Thermodynamic Modeling
}

\author{
Mattias Thuvander ${ }^{1, * \mathbb{D}}$, Hans Magnusson ${ }^{2}$ and Ulrika Borggren ${ }^{3}$ \\ 1 Division of Microstructure Physics, Department of Physics, Chalmers University of Technology, \\ SE-412 96 Göteborg, Sweden \\ 2 Thermomechanical Processes and Casting, Material Development, Swerim AB, Box 7047, Kista, \\ SE-164 07 Stockholm, Sweden; hans.magnusson@swerim.se \\ 3 Product Development, SSAB Europe, SE-781 84 Borlänge, Sweden; ulrika.borggren@sandvik.com \\ * Correspondence: mattias.thuvander@chalmers.se; Tel.: +46-31-772-3322
}

Citation: Thuvander, M.;

Magnusson, H.; Borggren, U. Carbide Precipitation in a Low Alloyed Steel during Aging Studied by Atom Probe Tomography and Thermodynamic Modeling. Metals 2021, 11, 2009. https://doi.org/10.3390/met11122009

Academic Editor: Angelo Fernando Padilha

Received: 17 November 2021 Accepted: 9 December 2021

Published: 13 December 2021

Publisher's Note: MDPI stays neutral with regard to jurisdictional claims in published maps and institutional affiliations.

Copyright: (c) 2021 by the authors. Licensee MDPI, Basel, Switzerland. This article is an open access article distributed under the terms and conditions of the Creative Commons Attribution (CC BY) license (https:// creativecommons.org/licenses/by/ $4.0 /)$.

\begin{abstract}
Carbide precipitation in martensitic low alloyed steels contributes to the mechanical properties through precipitation hardening. A high number density of carbides is desired to maximize the hardening effect, which is achieved through the precipitation of carbides on the dislocations in the martensitic structure. In this study, the nucleation, growth, and coarsening of vanadium and molybdenum carbides during aging at $600{ }^{\circ} \mathrm{C}$ for periods up to four weeks were investigated. The work covers characterization with atom probe tomography, which showed that the nucleation of $\mathrm{V}$ and Mo rich $\mathrm{MC} / \mathrm{M}_{2} \mathrm{C}$ carbides takes place on dislocations. The growth of these carbides proceeds by the diffusion of elements to the dislocations, which has been modeled using Dictra software, confirming the rate of the reaction as well as the depletion of carbide formers in the matrix. For longer aging times, particle coarsening will decrease the number density of particles with a transition from dislocation-based carbides to separate rounded carbides.
\end{abstract}

Keywords: carbides; precipitation; low-alloyed steel; atom probe tomography; thermodynamic modeling; aging

\section{Introduction}

Precipitates in steel contribute to the mechanical properties through a combination of precipitation hardening and refinement of the grain size. The mechanical properties of the material can be optimized by designing the precipitate type, size, and number density. Normally, a large number of small particles is desired compared to few and large particles. During processing, or in service at elevated temperatures, the precipitates start to grow and eventually coarsen, leading to a decrease in the material strength. Since the precipitates are in the size range of a few $\mathrm{nm}$, the microstructural changes causing the lower strength are not necessarily seen using conventional characterization methods such as optical microscopy and scanning electron microscopy (SEM).

In high strength low alloyed (HSLA) steels, additions of niobium, titanium, and vanadium, individually or in combination, have long been used to increase the strength by the precipitation of carbides, nitrides, and carbonitrides that are formed during thermomechanical treatments. Precipitation in HSLA steels has been investigated intensively (see, for example, [1-5]). As the precipitates are so small, the high magnification obtained using transmission electron microscopy (TEM) or atom probe tomography (APT) is needed to reveal individual precipitates and to determine their size, composition, and crystal structure (in the case of TEM) [6-10]. Small angle neutron scattering (SANS), on the other hand, can be used for quantitative measurements of the aggregated precipitate size distribution [11,12]. 
Precipitation of particles is often divided into three separate stages (although they can occur in parallel), namely nucleation, growth, and coarsening. Alloying elements of special interest in this work are molybdenum and vanadium, which normally precipitate as secondary carbides during aging around $500-600{ }^{\circ} \mathrm{C}$. These elements are relatively strong carbide formers and when added in low concentration in low-alloyed steels, they remain in solid solution during hot-working and quenching to room temperature, and then precipitate in the martensite structure during subsequent aging. Nucleation sites are crystal defects such as grain boundaries, lath boundaries, or dislocations. For a martensitic structure, there is normally a high density of dislocations, and this will often be the dominating nucleation site yielding a high number density of particles.

It is of interest to follow the precipitation sequence in the martensite of HSLA steels, and precipitation at dislocations has been reported to occur in several studies. Zhang et al. studied the softening of steels alloyed with $\mathrm{V}, \mathrm{Nb}$, and $\mathrm{Ti}$ aged at $350-750{ }^{\circ} \mathrm{C}$ [13]. An increase in hardness was achieved through alloying when aging at around $600{ }^{\circ} \mathrm{C}$. Characterization using APT revealed a network of precipitates located at dislocations after aging for a short time, $5 \mathrm{~min}$ at $650^{\circ} \mathrm{C}$. Shrestha et al. used APT to confirm that $\mathrm{Nb}$-rich clusters evolve to very fine nanosized precipitates in a $\mathrm{Nb}$-alloyed HSLA steel during aging at $800{ }^{\circ} \mathrm{C}$ for 10,20 , and $30 \mathrm{~s}$ [14]. Chen et al. investigated (Ti, Mo)C precipitation in both deformed and undeformed conditions for aging times of 5 and $60 \mathrm{~min}$ and temperatures of $650-700{ }^{\circ} \mathrm{C}$. It was found that the hardness decreased with increasing isothermal holding temperature and that there was a narrow hardness range for the deformed material [15]. Kobayashi et al. studied the influence of pre-deformation on the precipitation behavior of a ferritic steel when aging at $580^{\circ} \mathrm{C}$ [16]. Precipitation of discrete TiC-carbides was observed along the dislocations, especially for the pre-deformed material. Jiang et al. investigated steels with carbonitrides rich in $\mathrm{Mo}$ and $\mathrm{Nb}$ [10]. The main structure was bainite, which was aged at $650^{\circ} \mathrm{C}$. Different characterization methods were used, and APT showed the presence of particles along dislocations in the aged conditions.

The aim of the present study was to clarify the early stages of precipitation of secondary carbides in a martensitic structure, and how the precipitation evolves at longer times. Characterization was carried out using tensile testing, SEM, and APT, and the results were compared with computational thermodynamics. The major part of the work covers the APT of samples that were aged for different times. The series of experiments covers the precipitation sequence including nucleation, growth, and coarsening of Mo and V carbides in a martensitic structure. The experimental observations on the precipitate characteristics were used to determine how the computational tools could be used to predict the kinetics of the precipitation.

\section{Materials and Methods}

The investigated material was a low carbon steel with chemical composition according to Table 1. The material was delivered by SSAB, as austenitized, hot rolled, and water quenched in the hot-strip rolling mill. Small samples were taken from the hot rolled coil for further heat treatment and analysis. Tensile test specimens, together with smaller samples of the material, were aged in a laboratory furnace at $600^{\circ} \mathrm{C}$ for periods up to four weeks. A complementary test was made with $4 \mathrm{~h}$ aging at $500{ }^{\circ} \mathrm{C}$. The small aged samples were used for SEM analysis and for APT.

Table 1. The chemical composition of the investigated steel, given in $\mathrm{wt} \%$ with $\mathrm{Fe}$ as the balance.

\begin{tabular}{cccccc}
\hline C & Si & Mn & Cr & Mo & V \\
\hline 0.16 & 0.3 & 1.3 & 0.15 & 0.4 & 0.04 \\
\hline
\end{tabular}

To prepare specimens for APT, rods of approximate dimensions $15 \mathrm{~mm} \times 0.3 \mathrm{~mm} \times$ $0.3 \mathrm{~mm}$ were made by coarse cutting, grinding, and final cutting using a low-speed diamond saw. Ultra-sharp needle-shaped specimens were then prepared using a standard 
two-stage electropolishing procedure. In the first stage, a neck was created by polishing in a layer of a strong electrolyte $(10 \%$ perchloric acid in glycerol $(20 \%)$ and methanol $(70 \%)$ ) floating atop a heavy inert liquid (Galden $\left.{ }^{\circledR}\right)$. In the second stage, the entire rod was polished in a weak electrolyte ( $2 \%$ perchloric acid in 2-butoxyethanol) until the rod separated into two parts at the position of the neck made in the first stage. Some specimens were further polished using pulsed polishing (2-10 pulses of 1-10 ms duration) in the weak electrolyte to clean the surface. All polishing was made at around $17 \mathrm{~V}$. As the specimens are prone to oxidation, they were inserted into the vacuum of the APT instrument within a few minutes.

The atom probe used was a LEAP 3000X HR (Imago Scientific Instruments) with a detection efficiency of $37 \%$. All analyses presented here were made in laser pulse mode with a wavelength of $532 \mathrm{~nm}$ (green laser) at a pulse frequency of $200 \mathrm{kHz}$, laser pulse energy of $0.3 \mathrm{~nJ}$, set temperature of $50 \mathrm{~K}$, and evaporation rate of $0.2-0.5 \%$. The reconstructions were made using the voltage reconstruction scheme with an image compression factor of $1.65, k$-value of 4.0 , and evaporation field of $25 \mathrm{~V} / \mathrm{nm}$, using the IVAS 3.6 software (Cameca). The results are presented using atom maps and proximity histograms (proxigrams), obtained using iso-concentration surfaces (isosurfaces). Proxigrams are a kind of $1 \mathrm{D}$ concentration profiles, where the distances are defined relative to an isosurface, with negative distances for outside the particle and positive distances inside the particle [17]. In case there are several particles in the analyzed volume, the proxigram displays the average for all particles. For the creation of isosurfaces, the voxel size was $1.0 \mathrm{~nm}^{3}$ and the delocalization distances were $3.0 \mathrm{~nm} \times 3.0 \mathrm{~nm} \times 1.5 \mathrm{~nm}$, and suitable threshold concentrations were selected for each case. When evaluating the data, a few overlaps in the mass spectra had to be considered. These were primarily $\mathrm{C}_{2}{ }^{+}$and $\mathrm{C}_{4}{ }^{2+}(24 \mathrm{Da})$ and $\mathrm{C}_{4}{ }^{+}$and ${ }^{96} \mathrm{Mo}^{2+}(48 \mathrm{Da})$, which were handled using the isotopic abundances. For the atom maps of Mo, the peak at 48 Da was omitted.

Equilibrium calculations were made using the TCFE9 thermodynamic database with Thermo-Calc version 2020a (Thermo-Calc Software AB, Solna, Sweden). Simulations of particle growth were performed using the Dictra software. Thermo-Calc version 2020a was used together with the databases TCFE9 and MOBFE4. The simulations of particle growth were made considering the precipitation on dislocations. Thus, a cylindrical diffusion geometry was used. The size of the simulation cell was chosen with respect to the interdislocation spacing from which the growing particle takes matter from. The radius of the simulation cell was set to $50 \mathrm{~nm}$, which is half the particle and dislocation spacing, estimated from APT images.

A simplified chemistry was used in the Dictra simulations, Fe-0.16C-0.4Mo-0.04V (wt\%). Aging simulations at $600{ }^{\circ} \mathrm{C}$ were made for up to four weeks. The cubic carbide (FCC) was chosen as the precipitating phase in a martensitic matrix (BCC, ferrite). The results from the simulations were compared with the APT measurements. Three quantities were compared with the simulations in this work: average matrix composition during precipitation, particle size, and number density of particles.

\section{Results}

\subsection{Experimental Results}

\subsubsection{Mechanical Properties}

The ultimate tensile strength (UTS) values from the tensile tests of specimens aged at $600{ }^{\circ} \mathrm{C}$ for $1-40 \mathrm{~h}$ are shown in Figure 1, together with the value for the sample aged at $500{ }^{\circ} \mathrm{C}$ for $4 \mathrm{~h}$. The UTS decreases with increasing aging time, presumably due to recovery of the dislocation structure, coarsening of carbides, and a decrease in carbon concentration of the matrix. The recovery reached further after $1 \mathrm{~h}$ at $600{ }^{\circ} \mathrm{C}$ than after $4 \mathrm{~h}$ at $500{ }^{\circ} \mathrm{C}$. 


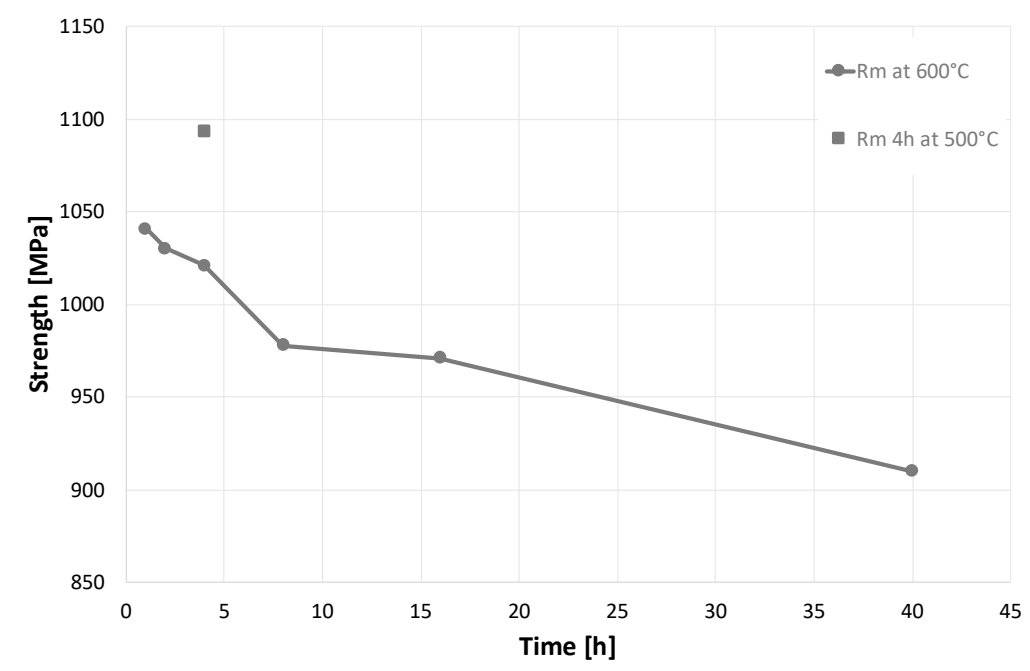

Figure 1. Tensile strength (UTS) as a function of aging time. The connected points are data from aging at $600{ }^{\circ} \mathrm{C}$ and the single point marked with a square is the sample aged at $500{ }^{\circ} \mathrm{C}$ for $4 \mathrm{~h}$.

\subsubsection{Scanning Electron Microscopy}

SEM was used to analyze the microstructure of the as-rolled and quenched sample and the sample aged for $4 \mathrm{~h}$ at $600{ }^{\circ} \mathrm{C}$, as shown in Figure 2. The as-rolled and quenched microstructure is martensitic with cementite formed due to auto-tempering during quenching. There are no carbides containing Mo and V formed after hot rolling and the rapid cooling to room temperature. Some degree of spheroidization of the cementite can be discerned after aging for $4 \mathrm{~h}$ at $600{ }^{\circ} \mathrm{C}$.

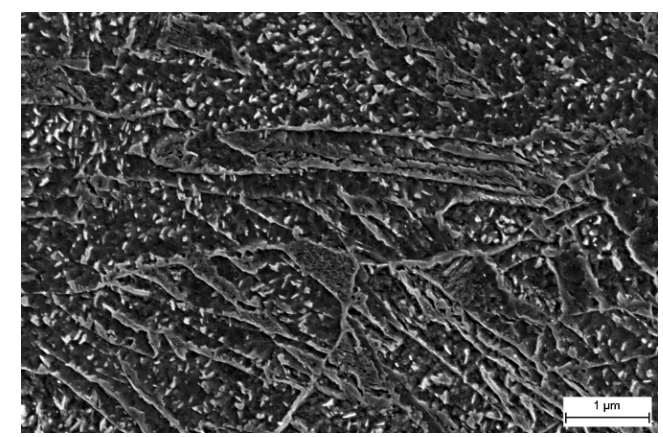

(a)

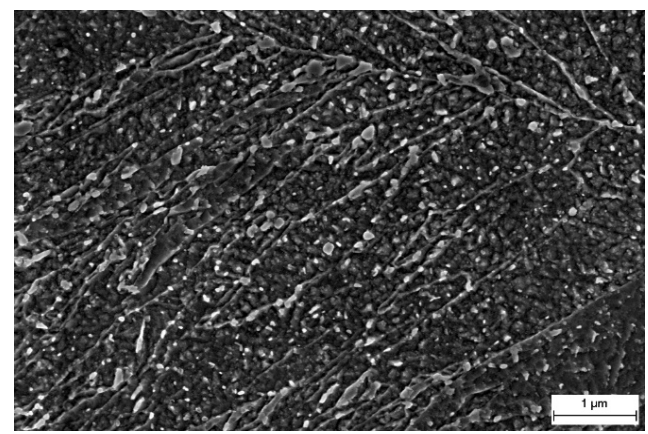

(b)

Figure 2. SEM images. (a) As-quenched. (b) After aging for $4 \mathrm{~h}$ at $600{ }^{\circ} \mathrm{C}$.

\subsubsection{Atom Probe Tomography}

The material conditions that were analyzed using APT were quenched, $4 \mathrm{~h}$ aging at $500{ }^{\circ} \mathrm{C}$, and $4,8,40 \mathrm{~h}$, and 4 weeks aging at $600{ }^{\circ} \mathrm{C}$. In the quenched material, all elements except carbon were homogeneously distributed. The reconstruction shown in Figure 3 contains both a primary carbide and segregation to a planar feature, which is likely a lath boundary. The measured $\mathrm{C}$ concentration of the carbide was close to $25 \mathrm{at} \%$, as expected for cementite $\left(\mathrm{Fe}_{3} \mathrm{C}\right)$. There was basically no enrichment of other elements in the $\mathrm{Fe}_{3} \mathrm{C}$-carbide. The concentration of $\mathrm{C}$ at the lath boundary was around 3 at \%. There was also some clustering of $\mathrm{C}$ in the matrix, some of which appears to be at dislocations, with a local $\mathrm{C}$ concentration of around 2 at $\%$. 

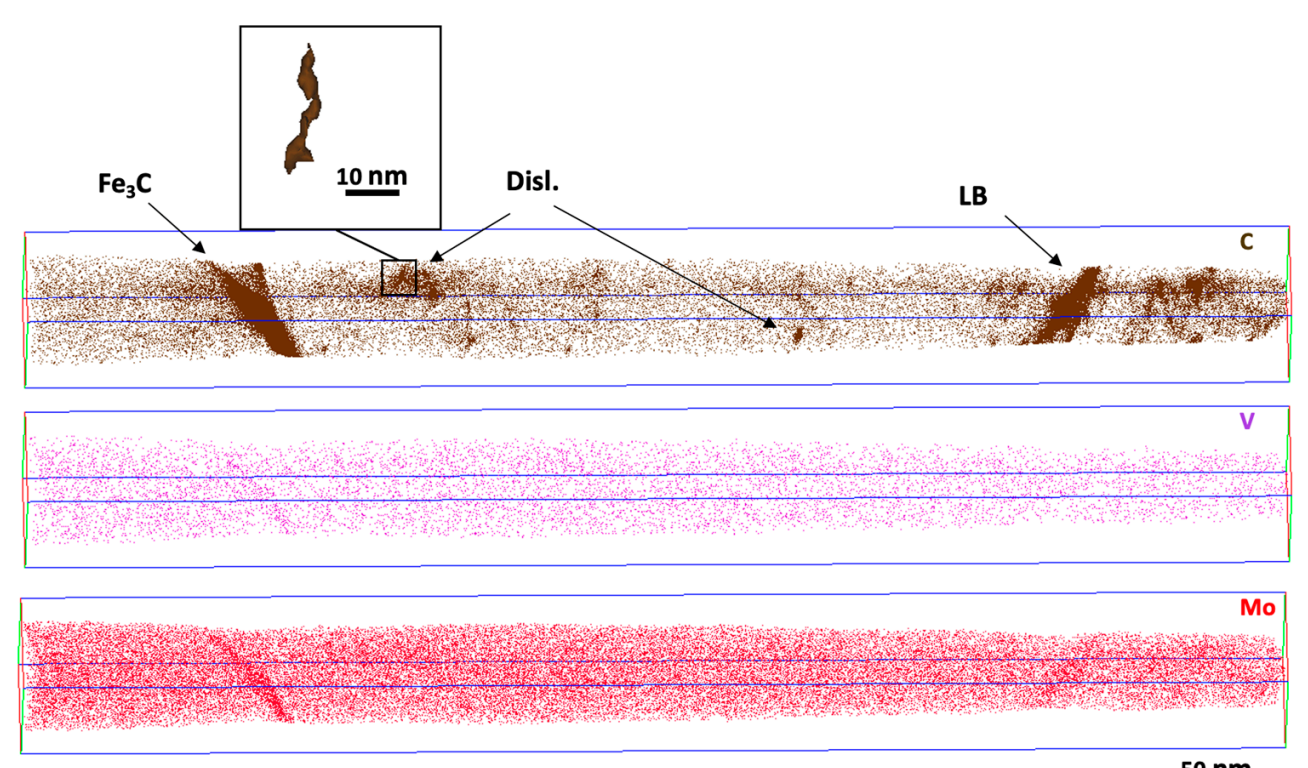

$50 \mathrm{~nm}$

Figure 3. Maps of all C, V, and Mo atoms in the quenched material. An $\mathrm{Fe}_{3} \mathrm{C}$ carbide (left) and segregation to a slightly curved lath boundary (LB) can be seen (right). There are also some very small carbon enrichments in the matrix. Some of these are elongated along presumed dislocations, as shown in the (rotated) insert, which shows an isosurface of $1.2 \mathrm{at} \% \mathrm{C}$.

An atom map of $\mathrm{C}$ from the material aged $4 \mathrm{~h}$ at $500{ }^{\circ} \mathrm{C}$ is presented in Figure 4 . The analyzed volume contains rather large $\mathrm{Fe}_{3} \mathrm{C}$ carbides, with a rim enriched in $\mathrm{Mn}, \mathrm{Cr}$, and $\mathrm{Mo}$ (not shown). This suggests that these elements are activated during aging, diffusing to the cementite carbide in agreement with its equilibrium composition. Outside the large carbides, there is a depletion profile of Mn. In the matrix, very small agglomerations of carbon are present. Proxigrams of many such small carbides are shown in Figure 4. The small carbides are strongly enriched in $\mathrm{Mn}(>10$ at $\%)$ and they are somewhat enriched in Mo and Cr. There is also a very small enrichment of V. As these carbides are very small $(\mathrm{r} \leq 1 \mathrm{~nm})$, the measured $C$ concentration cannot reliably be used to determine the stoichiometry and type of the carbides [18]. However, as Mn is the mostly enriched element, the best guess is probably cementite $\mathrm{M}_{3} \mathrm{C}$. The carbides are, at least partly, located on dislocations. Compared to the small secondary carbides formed at $600{ }^{\circ} \mathrm{C}$, see below, the $\mathrm{Mn}$ concentration is very high, probably as a consequence of the steel containing much more $\mathrm{Mn}$ than the stronger carbide forming elements $\mathrm{V}$ and Mo, and that the diffusion distances are so short at $500{ }^{\circ} \mathrm{C}$, making $\mathrm{Mn}$ the most available element for carbide formation besides $\mathrm{Fe}$ at this temperature.

Atom maps of C, V, and Mo from the APT analysis of the sample aged $4 \mathrm{~h}$ at $600{ }^{\circ} \mathrm{C}$ are presented in Figure 5. In this condition, the dislocations are decorated with carbides, strongly enriched in Mo and V. Isosurfaces of 2 at $\% \mathrm{C}$ were constructed, and the corresponding proxigram is shown in Figure 6. The carbides at the dislocations were also enriched in Mn and Cr. They contained low levels of P (1 at \%), N (0.3 at \%) and B (0.02 at \%), meaning that these elements had a higher concentration in the carbides than in the matrix. The even distribution of $\mathrm{V}$ and Mo along the dislocations means that there is no sign of separation into different carbide types. The measured maximum $C$ concentration was about 30 at $\%$. The incorporation of $\mathrm{N}$ and $\mathrm{V}$ suggests that the carbides are, or are about to become, $\mathrm{MC}$, but they could also be $\mathrm{M}_{2} \mathrm{C}$. Figure 7 presents two atom maps showing all detected $\mathrm{Fe}, \mathrm{Mo}$, $\mathrm{V}$, and $\mathrm{C}$ ions in a thin slice $(0.6 \mathrm{~nm})$ of the reconstruction. The low-density regions are long and "worm-like" and have a relatively constant radius $(\leq 2 \mathrm{~nm})$. The straight edges (Figure 7a) suggest that the carbides are elongated along the dislocations, rather than being a string of spherical particles. The low apparent density is a clear indication that this is a phase of high evaporation field, typical for alloy carbides [18]. Two videos can be found 
in the Supplementary Materials. Video S1 shows the V atoms, and Video S2 shows the isosurfaces created with a threshold of $\mathrm{C}+\mathrm{V}+\mathrm{Mo}=3 \mathrm{at} \%$. From these videos, it is obvious that the carbides must be present along dislocations. This observation is similar to the Mn-rich carbides observed along dislocations after aging for $4 \mathrm{~h}$ at $450{ }^{\circ} \mathrm{C}$ in the work by Kwiatkowski da Silva et al., who studied a cold worked Mn-steel [19].
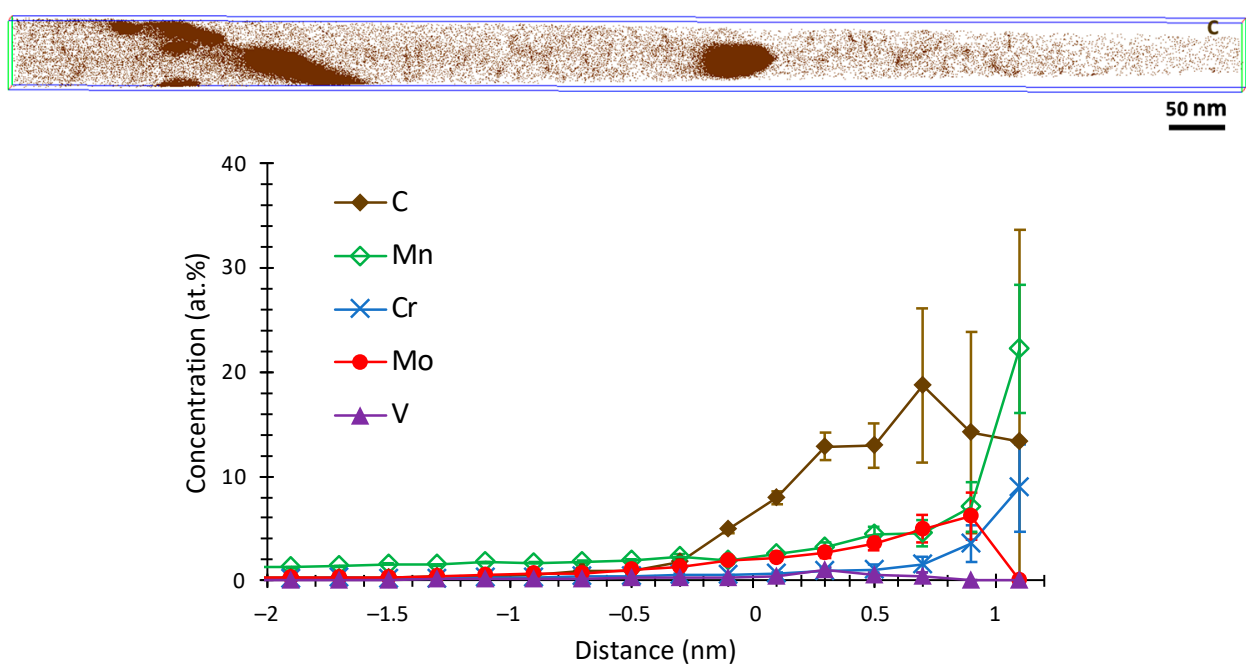

Figure 4. Atom map showing all $\mathrm{C}$ atoms in the sample aged $4 \mathrm{~h}$ at $500{ }^{\circ} \mathrm{C}$ (top). Cementite carbides at a lath boundary (left) and one large isolated carbide (right) are seen. There are also very small carbides in the matrix, for which a proxigram is presented (bottom).
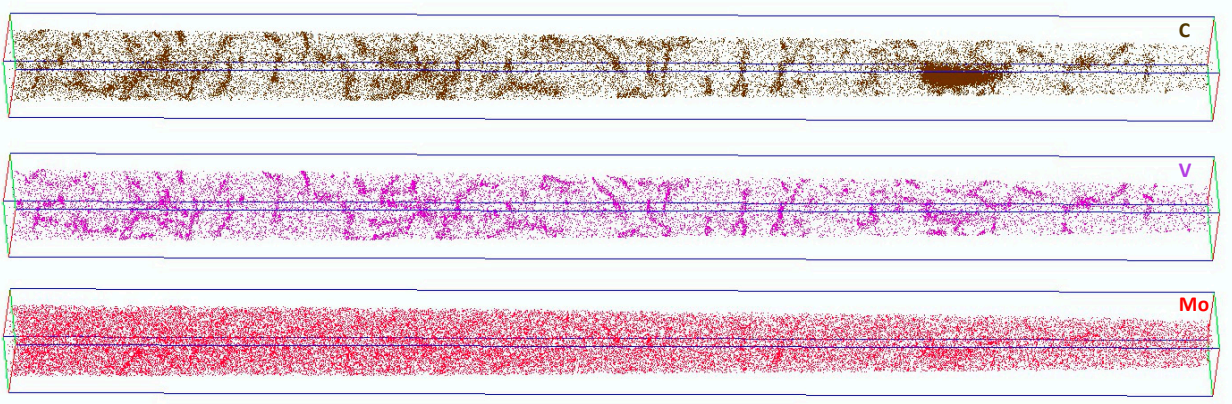

$50 \mathrm{~nm}$

Figure 5. Atom maps of the sample aged $4 \mathrm{~h}$ at $600{ }^{\circ} \mathrm{C}$. All atoms are shown for $\mathrm{C}$ and $\mathrm{V}$, and $30 \%$ for Mo (selected at random). Nucleation of secondary carbides along dislocations can be observed. A part of a large $\mathrm{Fe}_{3} \mathrm{C}$ carbide is seen in the right part of the image.

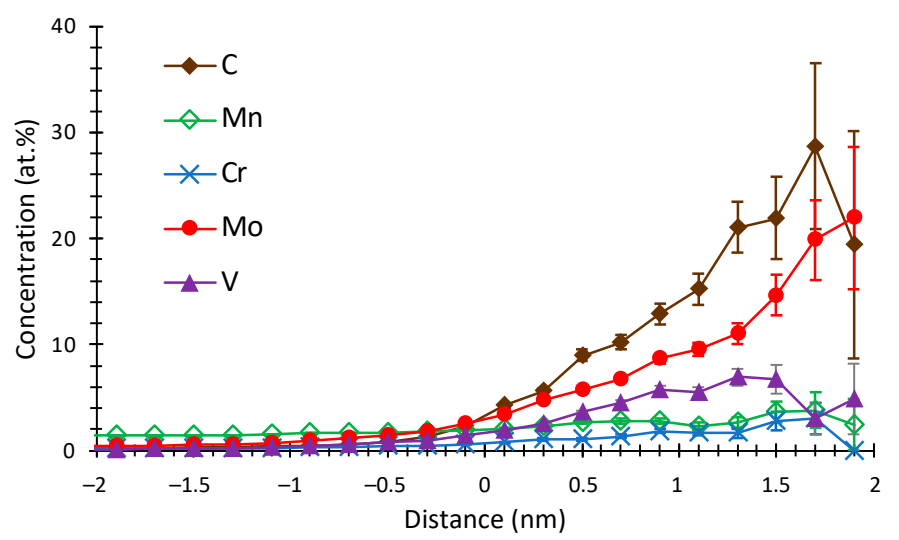

Figure 6. Proxigrams from the small carbides located on dislocations in Figure 5 from the sample aged $4 \mathrm{~h}$ at $600^{\circ} \mathrm{C}$. 


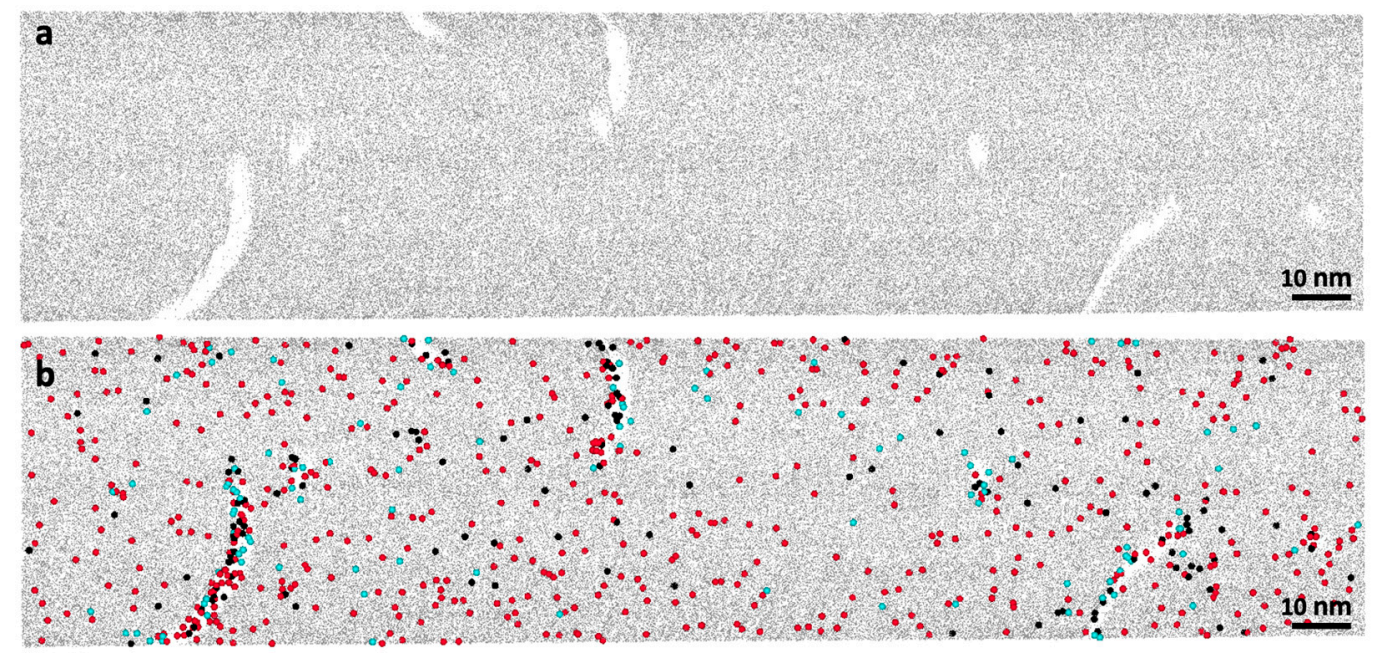

Figure 7. A $0.6 \mathrm{~nm}$ thick slice, from the sample aged $4 \mathrm{~h}$ at $600{ }^{\circ} \mathrm{C}$. (a) All detected ions of Fe (grey). (b) All detected ions of Fe (grey), Mo (red), V (turquoise), and C (black) are shown. To increase visibility, the atoms of Mo, $\mathrm{V}$, and $\mathrm{C}$ are drawn larger than the Fe atoms.

For the samples aged for $8 \mathrm{~h}, 40 \mathrm{~h}$, and four weeks at $600{ }^{\circ} \mathrm{C}$, carbon atom maps are presented in Figure 8. There were still carbides present along dislocations after $8 \mathrm{~h}$, but were much shorter and thinner compared to the $4 \mathrm{~h}$ sample, but after the two longer periods, there were no signs of carbides at dislocations. The very few carbides observed after $40 \mathrm{~h}$ and four weeks were round and rich in $\mathrm{V}$ and Mo, and they were present at lath boundaries, and not any longer at dislocations. In the analysis of the sample aged for four weeks, the analyzed volume contained a lath boundary with two MC carbides that contained slightly more Mo (27 at $\%)$ than V (21 at $\%)$. In this case, the measured C concentration was close to 50 at $\%$, supporting the assumption that they were indeed $\mathrm{MC}$. There was also surely some cementite present, but no such carbides were observed in the investigated volumes. In the analysis of the material aged for $8 \mathrm{~h}$, two large Fe-carbides (presumably $\mathrm{Fe}_{3} \mathrm{C}$, see Figure 8) with enrichments of $\mathrm{Mn}, \mathrm{Cr}$, Mo, and $\mathrm{V}$ were observed.

$8 \mathrm{~h}$

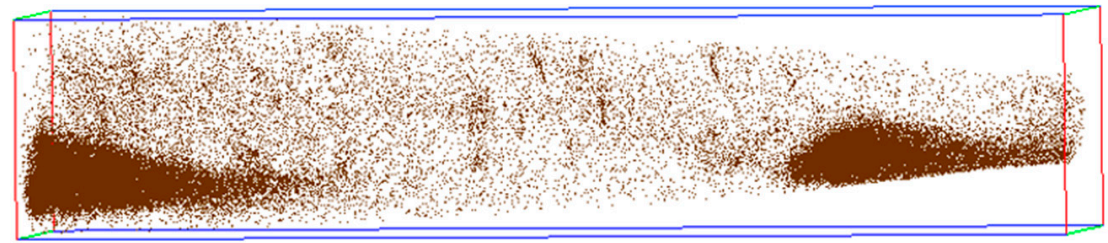

$40 \mathrm{~h}$
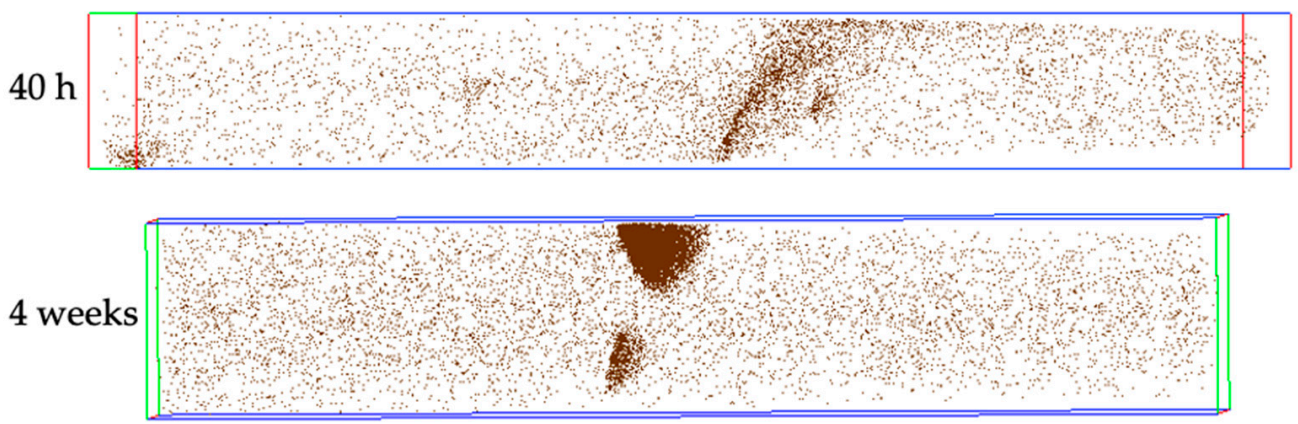

$50 \mathrm{~nm}$

Figure 8. Atom maps showing all $\mathrm{C}$ atoms in samples aged at $600{ }^{\circ} \mathrm{C}$ for $8 \mathrm{~h}, 40 \mathrm{~h}$, and four weeks. The analysis of the $8 \mathrm{~h}$ sample contains two large $\mathrm{Fe}_{3} \mathrm{C}$ and several small elongated carbides enriched in Mo and V. The carbides seen in the sample aged for four weeks are MC, rich in Mo and V. 
Figure 9 shows a proxigram, constructed using isosurfaces of $\mathrm{C}+\mathrm{Mo}+\mathrm{V}=3 \mathrm{at} \%$, from all the small carbides, all containing Mo and V, in the sample aged for $8 \mathrm{~h}$. Some of these carbides were located on dislocations, but some might not necessarily have been located on dislocations. These carbides were smaller than in the $4 \mathrm{~h}$ sample, suggesting that they were dissolving, providing $\mathrm{C}, \mathrm{V}$, and Mo to larger carbides that were growing (i.e., coarsening was taking place). The composition of the small carbides was similar to the composition after $4 \mathrm{~h}$, as can be seen when comparing the proxigrams in Figures 6 and 9. In another analysis of the $8 \mathrm{~h}$ sample, V-dominated MC carbides (diameter 3-5 nm) were observed at a lath boundary (not shown here).

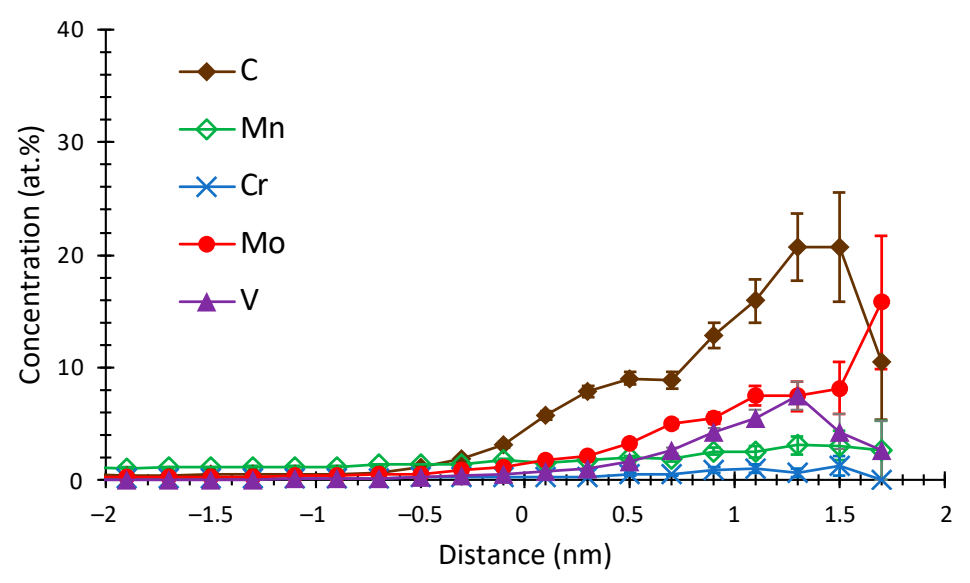

Figure 9. Proxigrams from the small carbides located in the matrix (likely on dislocations) from the sample aged $8 \mathrm{~h}$ at $600{ }^{\circ} \mathrm{C}$ (see Figure 8).

We attempted to measure the composition of the matrix (i.e., after removing the large carbides, and in the case of the $600{ }^{\circ} \mathrm{C}$ series, also the small carbides at the dislocations). The results are shown in Table 2. In general, there was a trend showing a decrease in matrix concentration of $\mathrm{C}, \mathrm{Cr}, \mathrm{Mo}$, and $\mathrm{V}$ with aging time, but there was a large spread. This can partly be due to some degree of macro/micro-segregation or the local martensite transformation temperature.

Table 2. Matrix composition (at $\%$ ) of the six conditions of the material from APT (after removing the carbides in the reconstructions).

\begin{tabular}{ccccccc}
\hline Element & Quenched & $\mathbf{5 0 0}{ }^{\circ} \mathbf{C} / \mathbf{4} \mathbf{h}$ & $\mathbf{6 0 0}{ }^{\circ} \mathbf{C} / \mathbf{4} \mathbf{h}$ & $\mathbf{6 0 0}{ }^{\circ} \mathbf{C} / \mathbf{~ h}$ & $\mathbf{6 0 0}{ }^{\circ} \mathbf{C} / \mathbf{4 0} \mathbf{h}$ & $\mathbf{6 0 0}{ }^{\circ} \mathbf{C} / \mathbf{4 ~ w}$ \\
\hline $\mathrm{C}$ & 0.070 & 0.019 & 0.030 & 0.072 & 0.042 & 0.014 \\
\hline $\mathrm{Si}$ & 0.60 & 0.68 & 0.93 & 0.41 & 0.30 & 0.58 \\
$\mathrm{Mn}$ & 1.16 & 1.14 & 1.24 & 0.80 & 0.88 & 1.02 \\
$\mathrm{Cr}$ & 0.24 & 0.15 & 0.16 & 0.14 & 0.11 & 0.10 \\
$\mathrm{Mo}$ & 0.22 & 0.19 & 0.20 & 0.13 & 0.082 & 0.10 \\
$\mathrm{~V}$ & 0.042 & 0.039 & 0.029 & 0.017 & 0.006 & 0.008 \\
$\mathrm{Ni}$ & 0.045 & 0.022 & 0.027 & 0.037 & 0.038 & 0.020 \\
$\mathrm{P}$ & 0.022 & 0.005 & 0.010 & 0.003 & 0.001 & 0.005 \\
\hline
\end{tabular}

\subsection{Computational Work}

\subsubsection{Equilibrium Calculations with Thermo-Calc}

Equilibrium phase fractions as a function of temperature are presented in Figure 10. Some phases are excluded in the calculations since they will most likely not form due to slow diffusion and difficulty in reaching equilibrium, and therefore are rarely seen for this type of steel. This includes hexagonal MC (WC-type), some chromium carbides $\left(\mathrm{M}_{7} \mathrm{C}_{3}\right.$ and $\mathrm{M}_{23} \mathrm{C}_{6}$ ), and other Mo-based carbides. The main stable phases were cementite as the major carbide together with both the hexagonal $\mathrm{M}_{2} \mathrm{C}$ and the cubic MC. Typical compositions of 
the stable carbides are given in Table 3. The cubic carbide $\mathrm{MC}$ is rich in $\mathrm{V}$, and the hexagonal $\mathrm{M}_{2} \mathrm{C}$ is rich in Mo. Cementite is mainly an iron carbide, with relatively high solubility of $\mathrm{Mn}$ according to the equilibrium calculations, which agrees with the APT measurements.

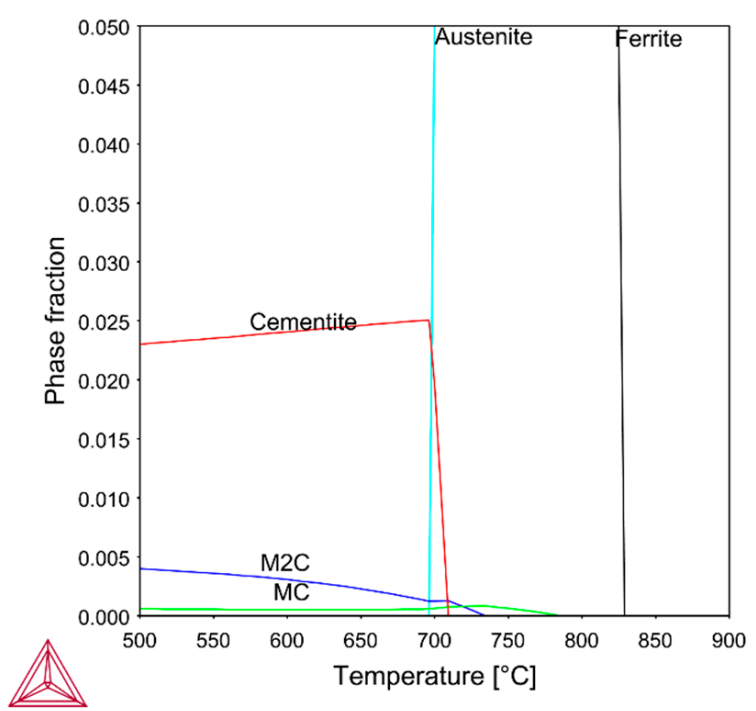

Figure 10. Equilibrium calculation for the nominal composition, based on the TCFE9 database with Thermo-Calc.

Table 3. Calculated composition of carbides at $600{ }^{\circ} \mathrm{C}$ using Thermo-Calc, with values given in at $\%$.

\begin{tabular}{ccccccc}
\hline Carbide & Mo & V & Mn & Cr & C & Fe \\
\hline MC-type & 6.3 & 38.3 & 0.3 & 0.5 & 47.0 & 7.5 \\
M $_{2}$ C-type & 52.2 & 6.2 & 6.0 & 0.9 & 33.3 & 1.4 \\
Cementite & 0.3 & 0.1 & 14.2 & 3.2 & 25.0 & 57.1 \\
\hline
\end{tabular}

\subsubsection{Particle Growth Simulations with Dictra}

The APT characterization revealed that the secondary carbides precipitated on the dislocations in the structure, as shown in Figure 5. The particle growth was therefore simulated based on the assumption that the nucleation event is on the dislocations, and that the particles grow by diffusion from the matrix to the particles according to a cylindrical geometry. The simulation cell was set to $50 \mathrm{~nm}$, which is estimated as half the interdislocation spacing. High-temperature lattice diffusion data were used, which should be reasonable since the major part of the elements is taken from positions being in-between the dislocations of the dislocation network.

The simulated growth of the carbides will deplete the matrix of its alloying elements. The simulation results were compared with the APT values (Table 2), as presented in Figure 11. With time, both Mo and V will diffuse toward the growing carbides and the content of these elements will decrease in the matrix. The simulated values are the integrated values in the whole matrix phase, which is seen as an average value of the matrix composition. A quite good agreement was seen with the loss of both elements due to particle growth. Most of the alloying elements precipitated after $25 \mathrm{~h}$ at $600{ }^{\circ} \mathrm{C}$, although the $40 \mathrm{~h}$ APT measurement of Mo indicated that some Mo should remain in solution whereas the simulations predicted that most of the Mo should be consumed by the precipitation. 


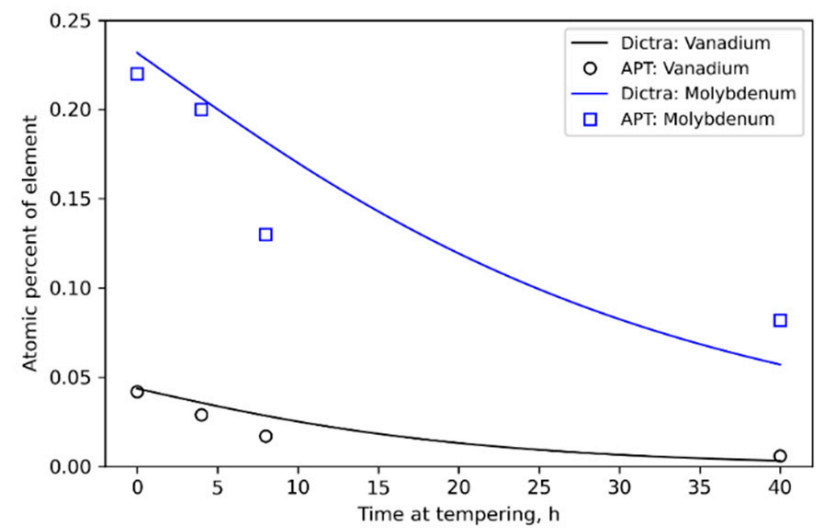

Figure 11. Concentration (at \%) of Mo and V according to APT measurements of matrix composition and Dictra simulations of total content in the matrix at isothermal aging at $600{ }^{\circ} \mathrm{C}$.

At early stages of precipitation, carbide growth occurs through the diffusion of elements to the carbides located on the dislocations. At longer times, these dislocation particles will become discrete spherical carbides, as shown in the APT measurements. The Dictra simulation was conducted to capture the early stage of precipitation, with an increase in particle diameter of the cylindrical particles located at the dislocation. The simulated particle diameters are shown in Figure 12. Particle growth is strongly temperature dependent, and nearly no growth should be expected at $500{ }^{\circ} \mathrm{C}$, and a size of a few nanometers at $600{ }^{\circ} \mathrm{C}$, in general agreement with observations in this work. Due to the formation of spherical particles, the simulations are not valid for longer times.

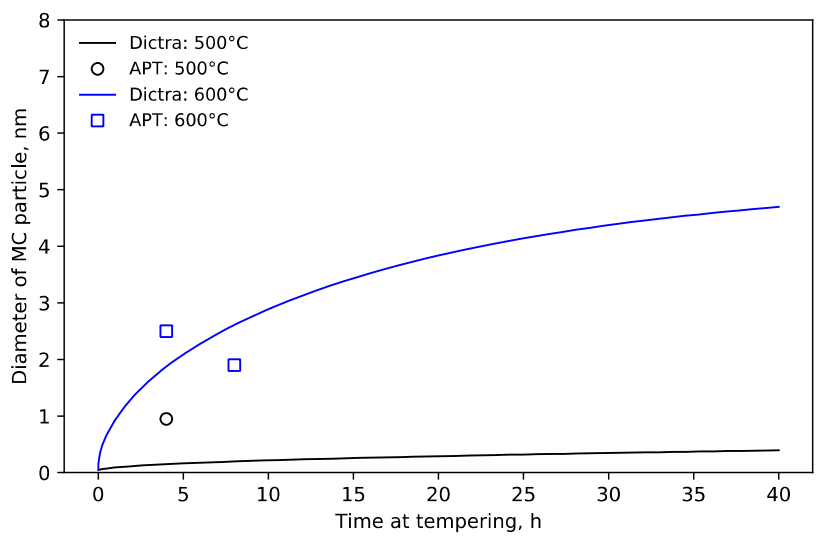

Figure 12. Simulated size of MC carbides according to Dictra, and a rough estimate from APT analysis. The size denotes the diameter of the elongated cylindrical particles at isothermal holding at $600^{\circ} \mathrm{C}$.

\section{Discussion}

Precipitation of carbides, through nucleation and growth, is diffusion controlled and will take time. Precipitation of iron carbides, which is mainly controlled by carbon diffusion, will commence directly at quench from high temperature in a few seconds to room temperature. Carbon diffusion is several orders of magnitude faster than the diffusion of metallic elements. The quenched state investigated in this study showed the presence of iron carbides and carbon segregations. No small carbides rich in $\mathrm{V}$ and Mo were observed for this condition.

Precipitation of secondary carbides rich in metallic alloying elements will require more time for diffusion to provide the elements from the matrix, which is strongly affected by temperature. The APT work highlighted that precipitation of V and Mo carbides barely started after aging for $4 \mathrm{~h}$ at $500{ }^{\circ} \mathrm{C}$. Some few discrete particles were seen at this early 
stage of precipitation, most likely located at dislocations. The rate of carbide precipitation will depend on the rate of diffusion of alloying elements to the growing particle, and the concentration difference at the particle/matrix interface. The growing carbide has a high concentration of these elements, around $50 \mathrm{at} \%$ in total for the cubic carbide. The growing carbide is supplied with $\mathrm{V}$ and Mo from the matrix, which has low nominal concentration of these elements. The combination of slow diffusion and large concentration differences will lead to a slow precipitation of $\mathrm{V}$ and Mo carbides. On the other hand, some $\mathrm{Mn}$ partitioning to the iron-carbide shells were seen already after $4 \mathrm{~h}$ aging at $500^{\circ} \mathrm{C}$, driven by a higher concentration of $\mathrm{Mn}$ in the matrix and less in the carbide. In a simplified view, the diffusion length of Mn could be judged to be around $5 \mathrm{~nm}$ from the APT measurement (not shown), and assuming that the diffusion length is approximately equal to $(2 \mathrm{Dt})^{1 / 2}$ gives $\mathrm{D}$ about $9 \times 10^{-22} \mathrm{~m}^{2} / \mathrm{s}$. This is similar to the value of self-diffusion of Fe in bcc-Fe at $500{ }^{\circ} \mathrm{C}$ of $3.0 \times 10^{-22} \mathrm{~m}^{2} / \mathrm{s}$ given in literature [20]. The corresponding value for $\mathrm{Mn}$ in bcc-Fe is missing at $500{ }^{\circ} \mathrm{C}$, but for higher temperatures, Mn diffuses faster than Fe self-diffusion in ferrite.

Aging at $600{ }^{\circ} \mathrm{C}$ for $4 \mathrm{~h}$ showed a more significant precipitation of $\mathrm{V}$ and Mo at the dislocations in the martensitic structure. The dislocations are clearly highlighted by these elements in the 3D APT atom maps. The controlling mechanism for precipitation seems to be the diffusion of $\mathrm{V}$ and Mo to the dislocations, taking place at inter-dislocation positions. The diffusion distances are relative short, approximately $50 \mathrm{~nm}$ as inter-dislocation spacing, but some time is still required before the precipitation is complete. The observation after $4 \mathrm{~h}$ aging shows the possibility of capturing the precipitation sequence, with ongoing formation of carbides driven by the diffusion of elements to the dislocations. The samples aged for longer times than $4 \mathrm{~h}$ showed more spherical and discrete carbides, which seem to be driven by coarsening with the growth of individual particles probably supplied through diffusion along the dislocation network.

Diffusion simulations were made using the Dictra software. Dictra does not treat the nucleation step, and it was assumed that a nucleus was formed on the dislocation directly at the start of aging. A cylindrical growth model was used with symmetry along the dislocation line. The growth of the carbide was then simulated using lattice diffusion coefficients. A typical argument for low-temperature simulations is to use pipe-diffusion along dislocations, or grain-boundary diffusion, but in this case, the controlling mechanism seems to be inter-dislocation diffusion to the particles existing on dislocations, which can thus be captured by using lattice diffusion coefficients and a cylindrical geometry.

The simulation results were compared with the measured size and matrix contents of $\mathrm{V}$ and Mo. It is quite difficult to compare simulated particle sizes with observations due to the relatively few particles at longer times. In this study, the diameter of the particles on the dislocations were estimated and showed reasonable agreement with the simulations at short times. For the simulations, a cylindrical geometry was presumed for all aging times, but it was clear from APT that the carbides along the dislocations decreased in size between $4 \mathrm{~h}$ and $8 \mathrm{~h}$ of aging and after longer times, the carbides appeared to be round. Hence, the geometrical approach used for the simulations was only correct for short times $\left(<4-8 \mathrm{~h}\right.$ at $\left.600{ }^{\circ} \mathrm{C}\right)$ (i.e., as long as the carbides grow at the dislocations). Despite this fact, the simulated depletion of the matrix is in reasonable agreement with the measurements. In order to improve the simulations, it would be necessary to include a change from the growth of cylindrical carbides to spheroidal carbides. It is not known, however, if this takes place by a shape-change of existing carbides at the dislocations, or if these disappear completely while carbides at other locations such as lath boundaries grow.

In the Dictra simulation, one precipitate was considered, and the cubic carbide (FCC, MC) was chosen. However, according to the equilibrium calculation (Figure 10), both hexagonal $\left(\mathrm{HCP}, \mathrm{M}_{2} \mathrm{C}\right)$ and cubic carbides are stable. The cubic carbide was chosen instead of the hexagonal carbide, since it has a greater driving force for precipitation and will likely form first, which could at longer times transform in agreement with equilibrium to two types. A hexagonal carbide is expected to grow slightly faster compared to a cubic carbide 
due to a greater dependency of Mo instead of $\mathrm{V}$, however, in a ferrite matrix, the solubility of these elements is low and the diffusion problem becomes similar.

The simulated loss of $\mathrm{V}$ and Mo in the matrix due to precipitation was compared with the APT measurements, and the agreement was generally good. APT indicates that the concentration of elements in the matrix continues to fall after $8 \mathrm{~h}$ up to $40 \mathrm{~h}$ aging time. This suggests that the growth process is finished somewhere between $10-20 \mathrm{~h}$, as an estimate. On the other hand, the number density starts to decrease relatively early, already at $8 \mathrm{~h}$ aging when compared with the $4 \mathrm{~h}$ condition. The decrease in the number of carbides is a clear sign of particle coarsening. This observation indicates that the final stage of particle growth, and the early stage of coarsening, seem to occur in parallel. A reason for this could be the relatively fast diffusion of $\mathrm{V}$ and Mo along the carbide network, giving a faster coarsening, compared to the slower diffusion of elements at inter-dislocation positions based on lattice diffusion.

The mechanical properties of the investigated steel were also investigated. Particles and dislocations clearly interact in this martensitic grade. During nucleation, the high density of dislocations yields favorable positions to precipitate $V$ and Mo carbides. Hence, a high density of dislocations yields a high density of carbides, which should correspond to a significant particle hardening contribution. This hardening contribution is often seen for more highly alloyed materials such as tool steels, but for this low alloyed steel, the strength contribution from carbides was lower than the loss in strength due to the recovery of the martensitic structure and the overall strength decreased with aging time at $600{ }^{\circ} \mathrm{C}$. High-temperature aging will coarsen not only the particle structure, but also the dislocation structure. The APT measurements made in this work highlighted that dislocations should be efficiently pinned by particles during the initial stages of precipitation and recovery should be impaired. It is expected that further particle coarsening, with a decrease in carbide number density, could also lead to a more significant dislocation recovery with time.

\section{Conclusions}

The APT study showed that nucleation of vanadium- and molybdenum-rich secondary carbides takes place on dislocations to a large extent. At $600^{\circ} \mathrm{C}$ aging, it takes less than $4 \mathrm{~h}$ to decorate the dislocations with carbides, and presumably much longer at $500{ }^{\circ} \mathrm{C}$. Longer aging times at $600{ }^{\circ} \mathrm{C}$ resulted in coarsening of the carbides, and the formation of few, relatively large, more rounded carbides. The growth process and the coarsening process showed some overlap, with further loss of alloying elements in the matrix at longer times. Simulations suggest that the diffusion of elements to the growing carbides from the matrix in-between the dislocations can be accurately captured through the use of lattice diffusion, in the early stage. On the other hand, the coarsening of carbides is rapid, which could be explained by the presence of pipe-diffusion and diffusion along the dislocation networks, which was not captured in the present modeling.

Supplementary Materials: The following are available online at https://www.mdpi.com/article/10.3 390/met11122009/s1, Video S1: V-4h600C, Video S2: isosurfaces-4h600C.

Author Contributions: Conceptualization, M.T., H.M. and U.B.; Methodology, M.T., H.M. and U.B.; Writing—original draft preparation, M.T., H.M. and U.B.; Writing—review and editing, M.T., H.M. and U.B.; Visualization, M.T. All authors have read and agreed to the published version of the manuscript.

Funding: This research was funded by VINNOVA (Swedish Governmental Agency for Innovation Systems), grant no. 2015-06474.

Data Availability Statement: The data cannot be shared at the moment as they form part of an on-going study.

Acknowledgments: The authors would like to acknowledge Per Ngo for acquiring the SEM images, Robin Nilsson for performing the heat treatments, and Anders Rosvall and Lars-Erik Söderlind for the mechanical testing.

Conflicts of Interest: The authors declare no conflict of interest. 


\section{References}

1. Gladman, T. The Physical Metallurgy of Microalloyed Steels, 1st ed.; Institute of Materials: London, UK, 1997.

2. Lagneborg, R.; Siwecki, T.; Zajac, S.; Hutchinson, B. Role of vanadium in microalloyed steel. Scand. J. Metall. 1999, $28,186-241$.

3. Craven, A.J.; He, K.; Garvies, L.A.J.; Baker, T.N. Complex heterogeneous precipitation in titanium-niobium microalloyed Al-killed steels-I. (Ti,Nb)(C,N) particles. Acta Mater. 2000, 48, 3857-3868. [CrossRef]

4. Craven, A.J.; He, K.; Garvies, L.A.J.; Baker, T.N. Complex heterogeneous precipitation in titanium-niobium microalloyed Al-killed steels-II. Non-titanium based particles. Acta Mater. 2000, 48, 3869-3878. [CrossRef]

5. Chen, W.; Gao, P.; Wang, S.; Zhao, X.; Zhao, Z. Strengthening mechanisms of Nb and V microalloying high strength hot-stamped steel. Mater. Sci. Eng. A 2020, 797, 140115. [CrossRef]

6. Mukherjee, S.; Timokhina, I.B.; Zhu, C.; Ringer, S.P.; Hodgson, P.D. Three-dimensional atom probe study of interphase precipitation and nanoclusters in thermomechanically treated titanium-molybdenum steels. Acta Mater. 2013, 61, 2521-2530. [CrossRef]

7. Liu, Q.D.; Liu, W.Q.; Zhao, S.J. 3D atom probe characterization of temporal evolution of precipitates in aging $\mathrm{Nb}-\mathrm{V}$ micro-alloyed steel. Met. Mater. Int. 2012, 18, 1009-1013. [CrossRef]

8. Yi, H.-L.; Long, L.-Z.; Liu, Z.-Y.; Wang, G.-D. Investigation of precipitate in polygonal ferrite in a Ti-microalloyed steel using TEM and APT. Steel Res. Int. 2014, 85, 1446-1452. [CrossRef]

9. Timokhina, I.B.; Hodgson, P.D.; Ringer, S.P.; Zheng, R.K.; Pereloma, E.V. Precipitate characterisation of an advanced high-strength low-alloy (HSLA) steel using atom probe tomography. Scr. Mater. 2007, 56, 601-604. [CrossRef]

10. Jiang, L.; Marceau, R.K.W.; Guan, B.; Dorin, T.; Wood, K.; Hodgson, P.D.; Stanford, N. The effect of molybdenum on clustering and precipitation behaviour of strip-cast steels containing niobium. Materialia 2019, 8, 100462. [CrossRef]

11. Wang, Y.Q.; Clark, S.J.; Cai, B.; Alba Venero, D.; Yan, K.; Gorley, M.; Surrey, E.; McCartney, D.G.; Sridhar, S.; Lee, P.D. Small-angle neutron scattering reveals the effect of Mo on interphase nano-precipitation in Ti-Mo micro-alloys steels. Scr. Mater. 2020, 174, 24-28. [CrossRef]

12. Oba, Y.; Koppoju, S.; Ohnuma, M.; Murakami, T.; Hatano, H.; Sasakawa, K.; Kitahara, A.; Suzuki, J. Quantitative analysis of precipitate in vanadium-microalloyed medium carbon steels using small-angle X-ray and neutron scattering methods. ISIJ Int. 2011, 51, 1852-1858. [CrossRef]

13. Zhang, Y.; Zhao, C.; Sato, M.; Miyamoto, G.; Furuhara, T. Resistance to temper softening of low carbon martensitic steels by microalloying of $\mathrm{V}, \mathrm{Nb}$, and Ti. ISIJ Int. 2021, 61, 1641-1649. [CrossRef]

14. Shrsestha, S.; Xie, K.Y.; Zhu, C.; Ringer, S.P.; Killmore, C.; Carpenter, K.; Kaul, H.; Williams, J.G.; Cairney, J.M. Cluster strengthening of $\mathrm{Nb}$-microalloyed ultra-thin cast strip steels produced by the CASTRIP process. Mater. Sci. Eng. A 2013, 568, 88-95. [CrossRef]

15. Chen, C.-Y.; Chen, S.-F.; Chen, C.-C.; Yang, J.-R. Control of precipitation in the novel HSLA steel. Mater. Sci. Eng. A 2015, 634, 123-133.

16. Kobayashi, Y.; Takahashi, J.; Kawakami, K. Effects of dislocaitons on the early stage of TiC precipitation kinetics in ferritc steel: A comparative study with and without a pre-deformation. Acta Mater. 2019, 176, 145-154. [CrossRef]

17. Hellman, O.C.; Vandenbroucke, J.A.; Rüsing, J.; Isheim, D.; Seidman, D.N. Analysis of three-dimensional atom-probe data by the proximity histogram. Microsc. Microanal. 2000, 6, 437-444. [CrossRef] [PubMed]

18. Thuvander, M.; Shinde, D.; Rehan, A.; Ejnermark, S.; Stiller, K. Improving compositional accuracy in APT analysis of carbides using a decreased detection efficiency. Microsc. Microanal. 2019, 25, 454-461. [CrossRef]

19. Kwiatkowski da Silva, A.; Inden, G.; Kumar, A.; Ponge, D.; Gault, B.; Raabe, D. Competition between formation of carbides and reversed austenite during tempering of a medium-manganese steel studied by thermodynamic-kinetic simulations and atom probe tomography. Acta Mater. 2018, 147, 165-175. [CrossRef]

20. Neumann, G.; Tuijn, C. Self-Diffusion and Impurity Diffusion in Pure Metals: Handbook of Experimental Data, 1st ed.; Elsevier: Amsterdam, The Netherlands, 2009. 